\title{
Efficacy of Imatinib Mesylate Neoadjuvant Treatment for a Locally Advanced Rectal Gastrointestinal Stromal Tumor
}

\author{
Kyu Jong Yoon, Nam Kyu Kim, Kang Young Lee, Byung Soh Min, Hyuk Hur, Jeonghyun Kang, Sarah Lee ${ }^{1}$ \\ Departments of Surgery and ${ }^{1}$ Pathology, Yonsei University College of Medicine, Seoul, Korea
}

Surgery is the standard treatment for a primary gastrointestinal stromal tumor (GIST); however, surgical resection is often not curative, particularly for large GISTs. In the past decade, with imatinib mesylate (IM), management strategies for GISTs have evolved significantly, and now IM is the standard care for patients with locally advanced, recurrent or metastatic GISTs. Adjuvant therapy with imatinib was recently approved for use, and preoperative imatinib is an emerging treatment option for patients who require cytoreductive therapy. IM neoadjuvant therapy for primary GISTs has been reported, but there is no consensus on the dose of the drug, the duration of treatment and the optimal time of surgery. These are critical because drug resistance or tumor progression can develop with a prolonged treatment. This report describes two cases of large rectal malignant GISTs, for which a abdominoperineal resection was initially anticipated. The two patients received IM preoperative treatment; we followed-up with CT or magnetic resonance imaging to access the response. After 9 months of treatment, a multi-disciplinary consensus that maximal benefit from imatinib had been achieved was reached. We determined the best time for surgical intervention and successfully performed sphincter-preserving surgery before resistance to imatinib or tumor progression occurred. We believe that a multidisciplinary team approach, considerating the optimal duration of therapy and the timing of surgery, is required to optimize treatment outcome.

Keywords: Gastrointestinal stromal tumors; Imatinib; Ultralow anterior resection; Coloanal anastomosis; Neoadjuvant treatment

\section{INTRODUCTION}

Gastrointestinal stromal tumors (GISTs) are mesenchymal neoplasms that appear to be related to the interstitial cells of Cajal of the myenteric plexus $[1,2]$. GISTs are characterized by high immunoreactivity to the thyrosine kinase receptor KIT (CD117) [3]. Approximately 80-95\% of GISTs harbor mutations in the KIT gene $[4,5]$, and $5 \%$ have gain of function mutations in the platelet derived growth factor receptor-alpha (PDGFR- $\alpha$ ) gene [6]. Activating mutations in these genes trigger downstream signal pathways that cause increased cellular proliferation and decreased apopto-

Received: January 25, 2011 Accepted: May 14, 2011

Correspondence to: Nam Kyu Kim, M.D.

Department of Surgery, Yonsei University College of Medicine,

134 Sinchon-dong, Seodaemun-gu, Seoul 120-749, Korea

Tel: +82-2-2228-2105, Fax: +82-2-313-8289

E-mail:namkyuk@yuhs.ac

(c) 2011 The Korean Society of Coloproctology

This is an open-access article distributed under the terms of the Creative Commons Attribution NonCommercial License (http://creativecommons.org/licenses/by-nc/3.0) which permits unrestricted noncommercial use, distribution, and reproduction in any medium, provided the original work is properly cited. sis, ultimately leading to an aberrant growth, neoplasia [3]. GISTs span a wide clinical spectrum from benign to highly malignant and even metastatic [7], and harbor the potential risk of local and distant recurrence, making them difficult to cure $[8,9]$. Imatinib mesylate (STI-571; Glivec/Gleevec, Norvatis Pharmaceuticals, Basel, Switzerland), a KIT and PDGFR- $\alpha$ inhibitor, is now standard care for patients with locally unresectable or metastatic GISTs and was recently approved for use in the adjuvant therapy setting in the United States and Europe [10, 11].

\section{CASE REPORTS}

\section{Case 1}

A 56-year-old man was referred to our hospital complaining of a 6-month history of constipation and tenesmus. His past medical history was unremarkable. Standard laboratory tests of serum and urine showed no abnormalities. Carcinoembryonic antigen (CEA) and carbohydrate antigen 19-9 (CA19-9) were within normal limits. A clinical examination did not detect any palpable abdominal mass. Digital investigation of the rectum revealed a mass of approximately $8 \mathrm{~cm}$ in diameter on the left lateral rectal wall about $3.7 \mathrm{~cm}$ 
above the anal verge. The mass was hard, elastic, and immobile and had an irregular surface. Magnetic resonance imaging (MRI) revealed a lobulated tumor (measuring $9.0 \times 6.3 \mathrm{~cm}$ ) exhibiting intra- and extramural growth on the left lateral wall of the lower rectum, with compression displacement of the left levator muscle and prostatic gland, but there was no evidence of either pelvic lymphadenopathy or distant metastasis (Fig. 1A).

Transrectal ultrasound-guided biopsy samples showed the presence of a spindle cell tumor and immunohistochemical positivity for CD117 and CD34 (Fig. 1C, D), but was negative for $\alpha$-SMA, S-100 protein. From the results of these examinations, a rectal GIST was diagnosed.

Because of the high grade, size and localization of the lesion, imatinib mesylate (IM) neoadjuvant therapy was recommended. The patient, therefore, received IM therapy with a single daily dose of $400 \mathrm{mg}$ for 9 months and had follow-up within 3 months with CT scans to assess the therapeutic effect. During IM therapy, the tumor size continued to decrease (measuring $6.1 \times 3.6 \mathrm{~cm}$ ) and there were no side effects or evidence of progression. After 9 months of IM therapy, the CT and the MRI showed no remarkable size change, but a sharp demarcation had developed with respect to neighboring organs (Fig. 1B). He, therefore, underwent an ultralow anterior resection with direct coloanal anastomosis and diverting ileostomy. The ileostomy was closed 4 months after surgery.

The tumor, which measured $5 \times 4 \mathrm{~cm}$, was solid and had a well- demarcated white tan on the cut sections (Fig. 1E). Histopathology examination revealed that the tumor showed near total necrosis of tumor cells per 50 high power field (>95\%) (Fig. 1F). The resection margins were uninvolved on all sides, and there was no lymph node metastasis. The patient's postoperative course has been satisfactory and there has been no recurrence for 6 months without IM treatment.

\section{Case 2}

A 55-year-old man presented with a 12-month history of rectal pain and stool caliber change. A follow-up MRI showed a lobulated tumor (measuring $11.3 \times 10.7 \mathrm{~cm}$ ) arising from the anterior wall of the mid rectum, with upward displacement of the bilateral seminal vesicle and compression of the prostate (Fig. 2A). Tumor abutment was noted to the bladder base, prostate and proximal urethra. Abutment of the bilateral levator muscle without definite tumoral invasion was also noted, and several enlarged lymph nodes were found along the superior rectal vessel.

A transrectal ultrasound-guided biopsy showed a spindle cell stromal tumor with focal coagulative necrosis, mild cytologic atypia, and immunohistochemical positivity for CD117, CD34 and S-100 protein (Fig. 2C). The neoplastic cells were negative for $\alpha$-SMA and desmin. The pathologic findings were consistent with a highgrade GIST.

The patient began IM therapy at $400 \mathrm{mg}$ once daily, and was fol-
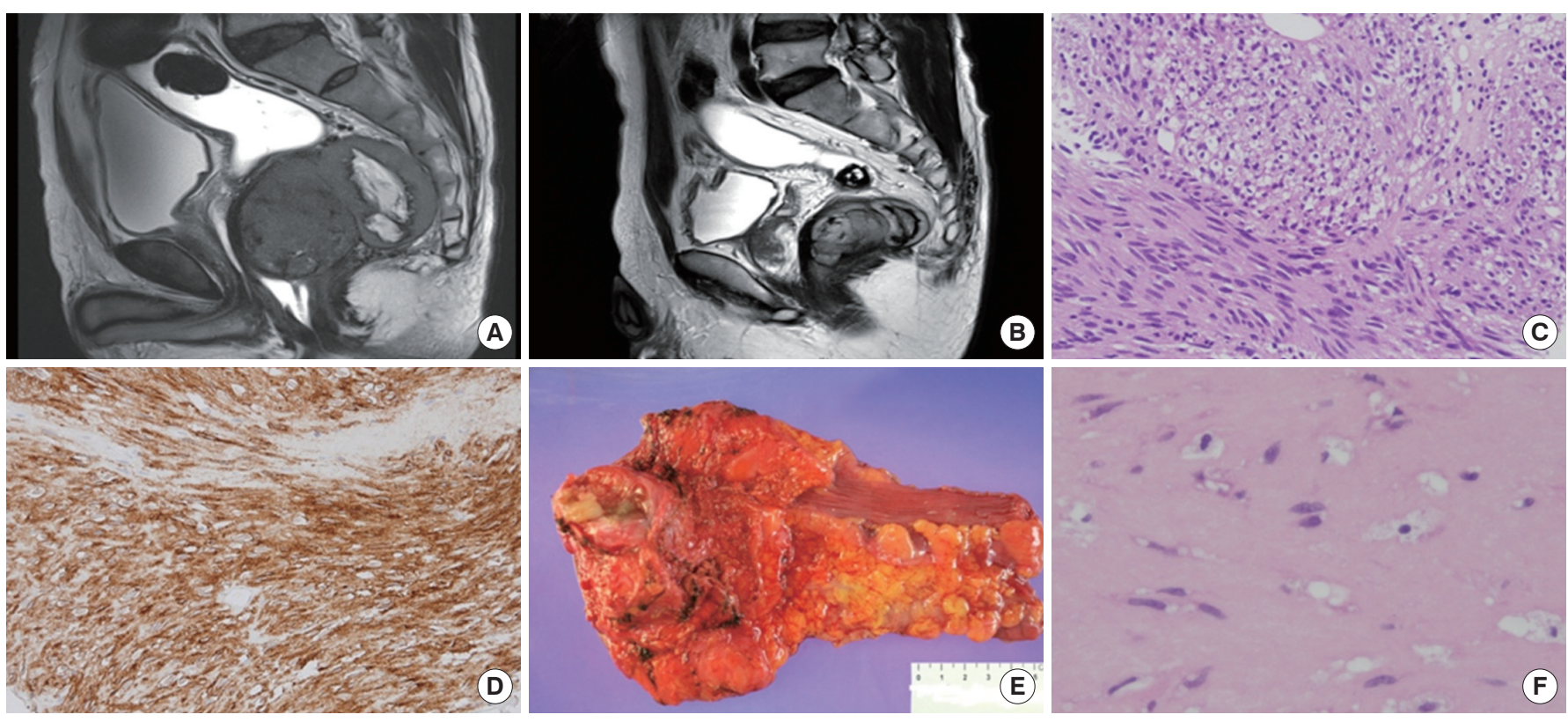

Fig. 1. Comparision of pre- and post-imatinib magnetic resonance imaging (MRI) and tumor tissue in case 1 undergoing neoadjuvant imatinib therapy. (A) MRI before imatinib therapy revealed a $9 \times 6.3 \mathrm{~cm}$ tumor with a necrotic portion involving the lower rectum. Compression displacement of the left levator muscle and prostatic gland can be seen. (B) MRI after 9 months of neoadjuvant imatinib therapy demonstrates a $6.1 \times 3.6 \mathrm{~cm}$ residual tumor. (C) Biopsy specimen before neoadjuvant therapy showing spindle-cell tumor cells $(\mathrm{H} \& \mathrm{E}, \times 200)$. (D) Immunohistochemical staining for c-kit was positive $(\mathrm{c}-\mathrm{Kit}, \times 200)$. (E) Gross specimen after neoadjuvant imatinib therapy demonstrating an ultralow anterior resection with a yellowish residual tumor mass. (F) Representative section of the tumor mass after imatinib therapy showing a hypocellular myxohyaline stroma $(\mathrm{H} \& \mathrm{E}, \times 400)$. 
Volume 27, Number 3, 2011

lowed-up within 3 months with CT scans. During IM therapy, the patient's rectal pain decreased. Side effects included fatigue and skin eruption. After 9 months of IM therapy, the CT and the MRI showed no remarkable size change (measuring $8.2 \times 4.5 \mathrm{~cm}$ ) and no evidence of progression, but still compressive abutment to the prostate, seminal vesicle, and levator muscle (Fig. $2 \mathrm{~B}$ ). He underwent an ultralow anterior resection with direct coloanal anastomosis, diverting ileostomy and radical cystectomy with an ileal conduit. The ileostomy was closed 2 months after surgery.

The tumor, which measured $8 \times 7 \mathrm{~cm}$, was solid and had a yellow tan parenchyma with focal calcification on the cut sections (Fig. 2D). Histopathology examination revealed that the tumor showed extensive hyalinization and calcification (Fig. 2E). The tumor cells were strongly positive for c-KIT (CD117) and CD34, and negative for $\alpha$-SMA and S-100 protein (Fig. 2F). There were more than 10 mitoses per 50 high-power field. The patient's postoperative course has been satisfactory, and there has been no recurrence for 12 months without IM treatment.

\section{DISCUSSION}

GISTs are the most common mesenchymal tumors of the gastrointestinal tract, with a worldwide incidence of approximately 15 per million [7]. GISTs occur throughout the GI tract, from the lower esophagus to the anus, but are found most commonly in the stom-
Table 1. Clinicopathological features of two cases

\begin{tabular}{lcc}
\hline & Case 1 & Case 2 \\
\hline Sex/age & Male/56 & Male/55 \\
Distance from AV $(\mathrm{cm})$ & 3.7 & 3 \\
Size $(\mathrm{cm})$ & $9.0 \times 6.3$ & $11.3 \times 10.7$ \\
CD 117 & Positive & Positive \\
CD 34 & Positive & Positive \\
Treatment duration (mo) & 9 & 9 \\
Side effects & None & Drug eruption \\
Residual size $(\mathrm{cm})$ & $6.1 \times 3.6$ & $8.2 \times 4.5$ \\
Opeartion & ULAR, CAA, & uLAR, CAA, \\
& diverting ileostomy & diverting ileostomy, \\
& & radical cystectomy, ICUD
\end{tabular}

$\begin{array}{lcr}\text { Mitosis }^{\text {a }} & \text { Rare } & >10 / 50 \\ \text { Follow-up } & & 12 \\ \text { Time (mo) } & 6 & \text { No } \\ \text { Recurrence (mo) } & \text { No }\end{array}$

ULAR, ultra-low anterior resection; CAA, coloanal anastomosis; ICUD, ileal conduit urinary diversion; HPF, high power field.

${ }^{a}$ Histopathological examination of case 1 revealed that the tumor showed near total necrosis of tumor cells per 50 high power field (>95\%).
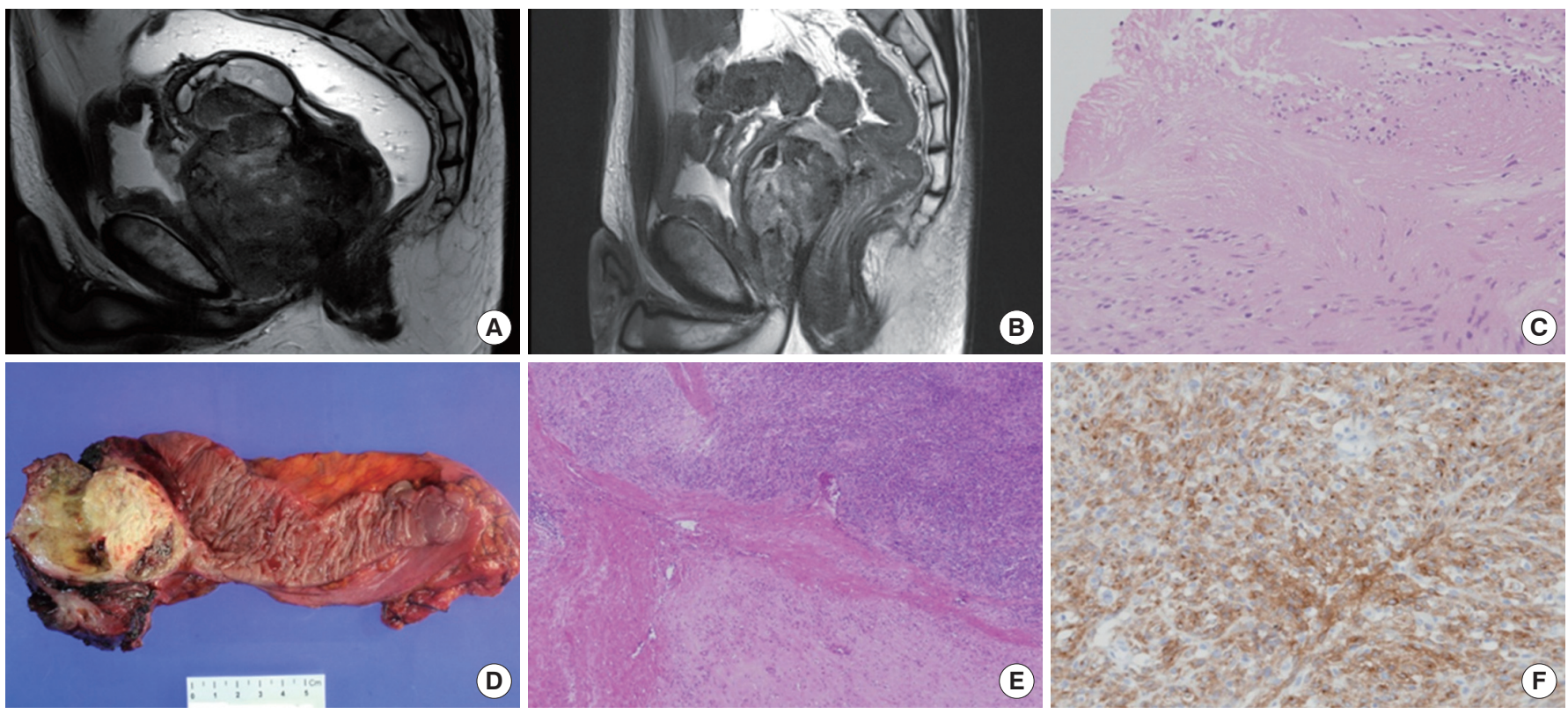

Fig. 2. Comparision of pre- and post-imatinib magnetic resonance imaging (MRI) and tumor tissue in case 2 undergoing neoadjuvant imatinib therapy. (A) MRI before imatinib therapy revealed a $11.3 \times 10.7 \mathrm{~cm}$, lobulated tumor arising from the anterior mesorectum of the low rectum. Abutment to the bladder base, the prostate and the bilateral levator muscle can be seen. (B) MRI after 9 months of neoadjuvant imatinib therapy shows a $9.5 \times 9 \mathrm{~cm}$ residual tumor. (C) Biopsy specimen before neoadjuvant imatinib treatment showing a spindle-cell stromal tumor with focal coagulotive necrosis and mild cytologic atypia (H\&E, $\times 200)$. (D) Gross specimen after neoadjuvant imatinib therapy demonstrating a yellowish residual tumor with attached prostate and seminal vesicles. (E) Representative section of the tumor mass after imatinib therapy showing extensive hyalinization $(\mathrm{H} \& \mathrm{E}, \times 40)$. (F) Microfocus of c-Kit positive tumor cells (c-Kit, $\times 200)$. 
ach (60\%), followed by the jejunum, ileum (30\%), duodenum (5\%), and colorectum $(<5 \%)[3]$. In Korea, only a few studies have been reported. In those studies, colorectal GISTs occurred predominantly in the rectum and tended to be classified as high risk, which was the most important risk factor for recurrence [12-14].

Diagnoses of GISTs in the rectum do not generally differ from those of other rectal tumors. Digital examination of the rectum, colonoscopy, and transrectal ultrasound are essential for diagnosis, together with a preoperative biopsy, which plays a key role in the diagnosis of GISTs. The preoperative biopsy provides information on immunohistochemical features such as CD117, CD34, and mitotic count. Furthermore, CT or MRI scanning is needed to determine the level of local invasion and to detect the presence of possible metastases. In 2007, the Korean GIST Study Group published the first clinical practice guidelines for accurate diagnosis and effective treatment of GISTs in Korea, which was updated in 2010 [15].

The management of GISTs has evolved rapidly since imatinib was introduced. The mainstay of treatment for primary GISTs has been surgical resection. Although surgery is the only known potentially curative treatment for primary or marginally resectable GISTs, 40$90 \%$ of surgically treated patients experience disease recurrence [16]. According to the 2002 US National Institutes of Health consensus criteria, the most relevant factors for risk stratification after resection of localized GISTs are tumor size and mitotic index [3]. More recently, evaluations of more than 1,600 patients by the Armed Forces Institute of Pathology led to an expansion in the prognostic criteria of localized GIST to include the tumor site, reflecting the fact that gastric GISTs are less aggressive than intestinal GISTs of the same size [17].

IM has been the standard first-line pharmacologic treatment in patients with locally unresectable, recurrent, or metastatic GISTs. In pivotal trials involving patients with advanced GISTs, IM has demonstrated an overall response rate (complete response plus partial response) in $68 \%$ of patients, a clinical benefit in $84 \%$ of patients, a median time to progression of 24 months, and a median overall survival of 57 months $[18,19]$. Because of such impressive clinical outcomes with IM monotherapy in advanced GISTs, IM has created interest in a variety of potential multimodal approaches that combine surgery with systemic therapy.

Recently, the ACOSOG Z9001 adjuvant trial of imatinib for primary GISTs indicated that this drug primarily benefited patients with larger tumors, which was manifested by enhanced diseasefree survival [20]. Based on the results of this trial, imatinib was recently approved as adjuvant therapy for GISTs by the US Federal Drug Administration and by the European Medicines Agency. However, the ideal dose and duration of imatinib in this setting remain a question. Several ongoing studies are evaluating the efficacy of adjuvant imatinib in patients with primary GISTs who are at high risk for postoperative relapse. The most recent management guidelines in the National Comprehensive Cancer Network and the European Society of Medical Oncology recommend adjuvant imatinib for at least 1 year following complete resection in patients with intermediate- to high-risk GISTs [21, 22].

Some patients with localized unresectable or metastatic GISTs may become candidates for surgery after response to imatinib treatment or a period of disease stabilization. Successful surgical resection has been reported in cases of previously unresectable disease following 3-12 months of imatinib therapy [21, 23]. Generally, maximal tumor response with no further decrease in size is reached after 6-12 months, and surgery can then be performed safely in the majority of cases [23]. Andtbacka et al. [24] compared the outcomes of preoperative IM therapy combined with surgery for locally advanced and metastatic GISTs among 46 patients, including 11 with locally advanced primary tumors and 35 with metastatic tumors. Complete surgical resection after IM neoadjuvant therapy was accomplished in all of the locally advanced primary tumors, but in only $31.4 \%(11 / 35)$ of the metastatic tumors. Based on these results, IM neoadjuvant therapy combined with surgery can be considered to be more effective for patients with primary GISTs. Neoadjuvant therapy with imatinib is being investigated for its effect on surgical outcomes.

Although treatment with imatinib results in a clinical response in the majority of advanced GIST patients, some patients are initially resistant or develop resistance to imatinib due to secondary mutations. Primary resistance to imatinib (progression within the first 6 months of therapy) is uncommon, but occurs in approximately $10 \%$ of patients, mostly those with mutations in KIT exon 9 or PDGFR- $a$ exon 18. Primary resistance is infrequently associated with secondary mutations. Approximately $67 \%$ of GIST patients develop secondary resistance to imatinib (progression after a minimum of 6 months of partial remission or SD) due to the appearance of secondary mutations, mainly in KIT exon 11 [25]. Determining the correct dosage of imatinib, the optimal duration of treatment and the best time of surgical intervention is, therefore, critical.

In our two cases, the patients responded to treatment with imatinib, as shown by CT or MRI for response assessment. After 9 months of IM neoadjuvant therapy, surgeons with multidisciplinary expertise, medical oncologists, radiologists, and gastroenterologists agreed that maximal benefit from imatinib had been achieved. We stopped the treatment and chose the surgical procedure before resistance to imatinib or tumor progression could occur. The postoperative courses of both patients have been satisfactory, and there have been no recurrences during the 6 - and 12-month subsequent periods without IM treatment (Table 1).

The role of IM neoadjuvant therapy has been discussed and explored in many clinical trials [23, 26-29], but the optimal duration of therapy has not yet been determined. Based on our prior experience and the findings from our two cases, we believe that clinical decision making for locally advanced rectal GISTs requires multidisciplinary expertise and that choosing the ideal time for surgery after neoadjuvant therapy is critical. Further study should define the role of neoadjuvant imatinib in GISTs to optimize treatment 
outcomes. A multidisciplinary team approach should be emphasized. In addition, large clinical trials are required to determine the optimal duration of therapy and the optimal timing of surgery.

\section{CONFLICT OF INTEREST}

No potential conflict of interest relevant to this article was reported.

\section{REFERENCES}

1. Miettinen M, Sarlomo-Rikala M, Lasota J. Gastrointestinal stromal tumors: recent advances in understanding of their biology. Hum Pathol 1999;30:1213-20.

2. Rubin BP, Fletcher JA, Fletcher CD. Molecular insights into the histogenesis and pathogenesis of gastrointestinal stromal tumors. Int J Surg Pathol 2000;8:5-10.

3. Miettinen M, Lasota J. Gastrointestinal stromal tumors: review on morphology, molecular pathology, prognosis, and differential diagnosis. Arch Pathol Lab Med 2006;130:1466-78.

4. Corless CL, Fletcher JA, Heinrich MC. Biology of gastrointestinal stromal tumors. J Clin Oncol 2004;22:3813-25.

5. Hirota S, Isozaki K, Moriyama Y, Hashimoto K, Nishida T, Ishiguro $\mathrm{S}$, et al. Gain-of-function mutations of c-kit in human gastrointestinal stromal tumors. Science 1998;279:577-80.

6. Heinrich MC, Corless CL, Demetri GD, Blanke CD, von Mehren $\mathrm{M}$, Joensuu $\mathrm{H}$, et al. Kinase mutations and imatinib response in patients with metastatic gastrointestinal stromal tumor. J Clin Oncol 2003;21:4342-9.

7. Sleijfer S, Wiemer E, Verweij J. Drug insight: gastrointestinal stromal tumors (GIST); the solid tumor model for cancer-specific treatment. Nat Clin Pract Oncol 2008;5:102-11.

8. DeMatteo RP, Lewis JJ, Leung D, Mudan SS, Woodruff JM, Brennan MF. Two hundred gastrointestinal stromal tumors: recurrence patterns and prognostic factors for survival. Ann Surg 2000;231: 51-8.

9. Pierie JP, Choudry U, Muzikansky A, Yeap BY, Souba WW, Ott MJ. The effect of surgery and grade on outcome of gastrointestinal stromal tumors. Arch Surg 2001;136:383-9.

10. European Medicines Agency (EMA). Committee for medicinal products for human use post-authorisation summary of positive opinion for glivec [Internet]. London, UK: EMA; 2009 [cited 2011 Jan 15]. Available from: http://www.ema.europa.eu/docs/en_GB/ document_library/Summary_of_opinion/human/000406/WC500059917.pdf.

11. U.S. Food and Drug Administration (FDA). Imatinib mesylate [Internet]. Silver Spring, MD: FDA; 2008 [cited 2011 Jan 15]. Available from: http://www.fda.gov/AboutFDA/CentersOffices/CDER/ ucm129210.htm.

12. Park KC, Kim HC, Park IJ, Yu CS, Kim JS, Kim JC. Clinicopathologic and immunohistochemical features of gastrointestinal stromal tumors (GISTs) in the colon \& rectum. J Korean Soc Coloproctol 2004;20:371-7.
13. Choi SH, Kim SJ, Choi YJ, Min BS, Kim JS, Baik SH, et al. Clinicopathologic analysis of gastrointestinal stromal tumors of the colon and rectum. J Korean Soc Coloproctol 2009;25:323-33.

14. Paek OJ, Kim YB, Oh SY, Suh KW. Gastrointestinal stromal tumors of the colon and rectum. J Korean Soc Coloproctol 2009;25: 318-22.

15. Kang YK, Kim KM, Sohn T, Choi D, Kang HJ, Ryu MH, et al. Clinical practice guideline for accurate diagnosis and effective treatment of gastrointestinal stromal tumor in Korea. J Korean Med Sci 2010;25:1543-52.

16. Rossi CR, Mocellin S, Mencarelli R, Foletto M, Pilati P, Nitti D, et al. Gastrointestinal stromal tumors: from a surgical to a molecular approach. Int J Cancer 2003;107:171-6.

17. Dematteo RP, Gold JS, Saran L, Gonen M, Liau KH, Maki RG, et al. Tumor mitotic rate, size, and location independently predict recurrence after resection of primary gastrointestinal stromal tumor (GIST). Cancer 2008;112:608-15.

18. Blanke CD, Rankin C, Demetri GD, Ryan CW, von Mehren M, Benjamin RS, et al. Phase III randomized, intergroup trial assessing imatinib mesylate at two dose levels in patients with unresectable or metastatic gastrointestinal stromal tumors expressing the kit receptor tyrosine kinase: S0033. J Clin Oncol 2008;26:626-32.

19. Demetri GD, von Mehren M, Blanke CD, Van den Abbeele AD, Eisenberg B, Roberts PJ, et al. Efficacy and safety of imatinib mesylate in advanced gastrointestinal stromal tumors. N Engl J Med 2002;347:472-80.

20. Dematteo RP, Ballman KV, Antonescu CR, Maki RG, Pisters PW, Demetri GD, et al. Adjuvant imatinib mesylate after resection of localised, primary gastrointestinal stromal tumour: a randomised, double-blind, placebo-controlled trial. Lancet 2009;373:1097-104.

21. National Comprehensive Cancer Network (NCCN). Clinical practice guidelines in oncology, soft tissue sarcoma [Internet]. Fort Washington, PA: NCCN; 2009 [cited 2011 June 2]. Available from: http://www.nccn.org/professionals/physician_gls/f_guidelines.asp.

22. Casali PG, Jost L, Reichardt P, Schlemmer M, Blay JY; ESMO Guidelines Working Group. Gastrointestinal stromal tumours: ESMO clinical recommendations for diagnosis, treatment and follow-up. Ann Oncol 2009;20 Suppl 4:64-7.

23. Bumming P, Andersson J, Meis-Kindblom JM, Klingenstierna $H$, Engstrom K, Stierner U, et al. Neoadjuvant, adjuvant and palliative treatment of gastrointestinal stromal tumours (GIST) with imatinib: a centre-based study of 17 patients. Br J Cancer 2003; 89:460-4.

24. Andtbacka RH, Ng CS, Scaife CL, Cormier JN, Hunt KK, Pisters PW, et al. Surgical resection of gastrointestinal stromal tumors after treatment with imatinib. Ann Surg Oncol 2007;14:14-24.

25. Heinrich MC, Corless CL, Blanke CD, Demetri GD, Joensuu H, Roberts PJ, et al. Molecular correlates of imatinib resistance in gastrointestinal stromal tumors. J Clin Oncol 2006;24:4764-74.

26. Baik SH, Kim NK, Lee CH, Lee KY, Sohn SK, Cho CH, et al. Gastrointestinal stromal tumor of rectum: a reoport of 7 cases. J Korean Surg Soc 2005;68:117-22. 
27. Oh JS, Lee JL, Kim MJ, Ryu MH, Chang HM, Kim TW, et al. Neoadjuvant imatinib in locally advanced gastrointestinal stromal tumors of the stomach: report of three cases. Cancer Res Treat 2006; 38:178-83.

28. Bonvalot S, Eldweny H, Pechoux CL, Vanel D, Terrier P, Cavalcanti A, et al. Impact of surgery on advanced gastrointestinal stromal tumors (GIST) in the imatinib era. Ann Surg Oncol 2006;13:1596-
603.

29. Rutkowski P, Nowecki Z, Nyckowski P, Dziewirski W, Grzesiakowska U, Nasierowska-Guttmejer A, et al. Surgical treatment of patients with initially inoperable and/or metastatic gastrointestinal stromal tumors (GIST) during therapy with imatinib mesylate. J Surg Oncol 2006;93:304-11. 